\title{
Co-design Processes to Address Nature-Based Solutions and Ecosystem Services Demands: The Long and Winding Road Towards Inclusive Urban Planning
}

\author{
Corina Basnou ${ }^{1 *}$, Joan Pino ${ }^{1,2}$, Clive Davies ${ }^{3,4}$, Georg Winkel ${ }^{3}$ and Rik De Vreese ${ }^{3}$ \\ ${ }^{1}$ CREAF, Cerdanyola del Vallès, Spain, ${ }^{2}$ Autonomous University of Barcelona, Cerdanyola del Vallés, Spain, ${ }^{3}$ European \\ Forest Institute (EFI Bonn), Bonn, Germany, ${ }^{4}$ Department of Architecture, Planning \& Landscape, Claremont Tower, \\ Newcastle University, Newcastle upon Tyne, United Kingdom
}

Keywords: stakeholder engagement, creative practice, nature-based solution, sustainable cities, facilitation, social-network

\section{INTRODUCTION}

The benefits and impacts that nature-based solutions (NBS) provide on the relationships between people and nature are widely recognized (Raymond et al., 2017). The NBS concept advocates the inclusion of a broad range of relevant actors in decision making (Pauleit et al., 2017), and co-

OPEN ACCESS

Edited by: Stephan Pauleit,

Technical University of

Munich, Germany

Reviewed by:

Anton Stahl Olafsson,

University of Copenhagen, Denmark

*Correspondence:

Corina Basnou

c.basnou@creaf.uab.es

Specialty section

This article was submitted to

Urban Greening,

a section of the journal

Frontiers in Sustainable Cities

Received: 14 June 2020 Accepted: 10 November 2020 Published: 09 December 2020

Citation:

Basnou C, Pino J, Davies C, Winkel G and De Vreese $R$ (2020) Co-design

Processes to Address Nature-Based Solutions and Ecosystem Services Demands: The Long and Winding Road Towards Inclusive Urban Planning.

Front. Sustain. Cities 2:572556. doi: 10.3389/frsc.2020.572556 design strategies are powerful approaches to include stakeholders and individual citizens on the same footing as professional actors (researchers, planners, politicians, decision makers, experts, institutional stakeholders). Co-design is a creative approach that enables bringing together real life experiences, views and skills of many different perspectives to address a specific problem (Szebeko and Tan, 2010). Co-design has considerable potential for jointly defining the challenges to be dealt with and the objectives for the solutions. Co-design supports jointly conceptualizing and delivering NBS when planning green infrastructure networks in urban environments (Karrasch et al., 2017). However, important gaps in knowledge, practice and planning remain when it comes to co-design in relation to NBS, green infrastructure and "green" governance.

We argue that co-design can help planners and policy makers to design green infrastructure which addresses not only ecological priorities, but also incorporates user demands and needs. Moreover, we believe that co-design supports planners and policy makers to better mainstream NBS into urban planning (Kabisch et al., 2016). Limitations exist, but we feel that co-design has great potential for cities committed to transformative change based on a "green" and "sustainable" agenda. In the following, we will further elaborate on these arguments.

\section{WHY DO WE NEED CO-DESIGN FOR TRANSFORMATIVE URBAN GREEN?}

A well-planned co-design process and engagement strategy supports inclusive participation and social learning through enabling knowledge, dialogue, learning, and equity in urban and territorial planning processes. It may better connect various citizen demands to expert knowledge, resulting in technical feasible and societally beneficial and supported outcomes. A society-relevant assessment of NBS needs to identify those actors that either benefit from or be harmed by an NBS (Raymond et al., 2017). Inclusive co-design should be particularly sensitive to cultural specifics and to challenges related to socio-environmental justice, biocultural diversity and gender ( $\mathrm{O}$ 'Brien et al., 2017). As a result, the co-design provides an arena for debate and elicitation of useful knowledge by and for all groups involved. It can be liberating for citizens to feel engaged in running the city. 
Co-design also allows identifying other key players through community knowledge, who might be missed because they are unknown to planning professionals. Co-design further gives visibility to the city and its citizens' projects, and allows finding synergies. Examples include offering practical assistance such as donating materials and staff volunteering through corporate social responsibility.

Co-design dynamics can help understanding social configurations and networks. As user perceptions are one important indicator of place-based ecological knowledge (Fish et al., 2016), perception mapping (perceived ES) can help researchers, planners and decision makers to understand and integrate societal demands on NBS (De Vreese et al., 2016). At the same time, co-design allows avoiding civic exclusion from NBS. Studies have argued for incorporating social network structures in applications of adaptive governance and comanagement (Bodin and Crona, 2009), bringing planners closer to collaborative ecosystem management through social learning, trust and social memory, which are all intertwined with social network structure (Ernstson et al., 2008).

Furthermore, co-design has a huge potential for raising awareness, engaging the stakeholders and increasing the sense of place (i.e., preserving local biodiversity). If the co-design workshop is considered as a "work-space," then the dynamics can follow the rules of a flipped classroom (i.e., a form of learning in which the teachers offer more personalized guidance and interaction with students, instead of only lecturing, Abeysekera and Dawson, 2015). Co-design techniques (i.e., workshops dynamics) should enable a shared vision, mutual learning and understanding for all stakeholders regardless of the position and power in local society. Continuing learning, including reiteration between steps, i.e., monitor and review, should be a key part of the process (Webb et al., 2019). That implies involving various tools (combining webinars or online videos that would proceed the co-design event; drawing, ideation cards or public participatory GIS during the sessions) and generating debate around the established objectives. Various methodologies can also be used to raise interest amongst participants from the very beginning, and to maintain their interests (i.e., social mapping, visual thinking, gamification, flipped classroom, outdoor learning etc.). Other examples include citizen science activities, social media, blogging, community events such as "discovery days" and conservation volunteering.

\section{ADAPTING TO THE (POST) COVID ERA}

A high quality co-design process is flexible to adapt research questions and methods. As new realities emerge (i.e., catastrophic events, such as the COVID-19 pandemic), these may converge into the dialogue on NBS, urban planning and co-design process. Local co-design workshops can explore the states of the respective NBS in specific cases and major challenges relating to its governance and management, and the NBS's further development/implementation (De Vreese et al., 2020). However, as the concepts of ES and NBS are not always in line with how local stakeholders perceive nature (De Vreese et al.,
2019), the co-design process should also allow for a flexible conceptualization of NBS and ES (NBS as a "boundary object," De Vreese et al., 2016). In the last months, people's needs for nature interaction, especially in urban environments, has been very prominent. In several countries, visitor numbers in urban and peri-urban green spaces increased by two or three-fold numbers (Derks et al., 2020). In other countries, where visits to green spaces and forests where interdicted, the nature-deficit syndrome (Louv, 2005) was present more than ever before (Grechyna, 2020). In both cases, society realized the huge potential of nature on health and well-being. From the green outside your window, through to urban greenspace design and close to nature living, there remains much to be ascertained about therapeutic effects of nature. It is reasonable to hypothesize that the force of nature on patients' recovery (i.e., in case of COVID 19) might be stronger than previously thought, giving place for therapeutic NBS close or even inside the hospitals. While cities are adopting new strategies of city renaturing and new mobility policies, by giving more opportunities to nature to develop (i.e., enabling the development of spontaneous vegetation or creating urban meadows in the case of Barcelona), new questions arise on how to mainstream NBS in planning. These questions encompass, for instance, how to re-engineer existing green spaces to be more multi-functional for pluralistic societies, and how to involve institutions such as schools and health centers to lever the restorative and therapeutic effects of green and blue spaces, including for disadvantaged communities. The latter can be an outcome of interconnections established during codesign processes.

\section{IMPACTS BEYOND PROJECT CYCLES}

A successful co-design strategy should also offer an output (i.e., actions), which will continue beyond the life of the project. Therefore, enabling capabilities became as important as improving tools or products that allow ongoing learning through development of communities of practice and knowledge (Webb et al., 2019). For example, the GREEN SURGE project created various Living labs and actions, created through inclusive codesign processes. The CLEARING HOUSE project will extend the Living Labs approach in ten urban forestry field labs in China and Europe. The "biodiverse edible schools" concept in Berlin links local urban nature and healthy food (Fischer et al., 2018). This project was based on collaborative activities in planning, managing and using the garden and the vacant site. We believe that co-design activities involving children and schools would not only benefit NBS and help to achieve inclusive urban planning, but also provides possibilities for nature experience and learning for children with potentially long lasting effects.

\section{DRAWBACKS}

Possible limitations can arise during the co-design process. For example, (i) stakeholders maps may always result in the same groups being addressed, driven by the expectations of planners and researchers, and (ii) co-design sessions or citizen science 


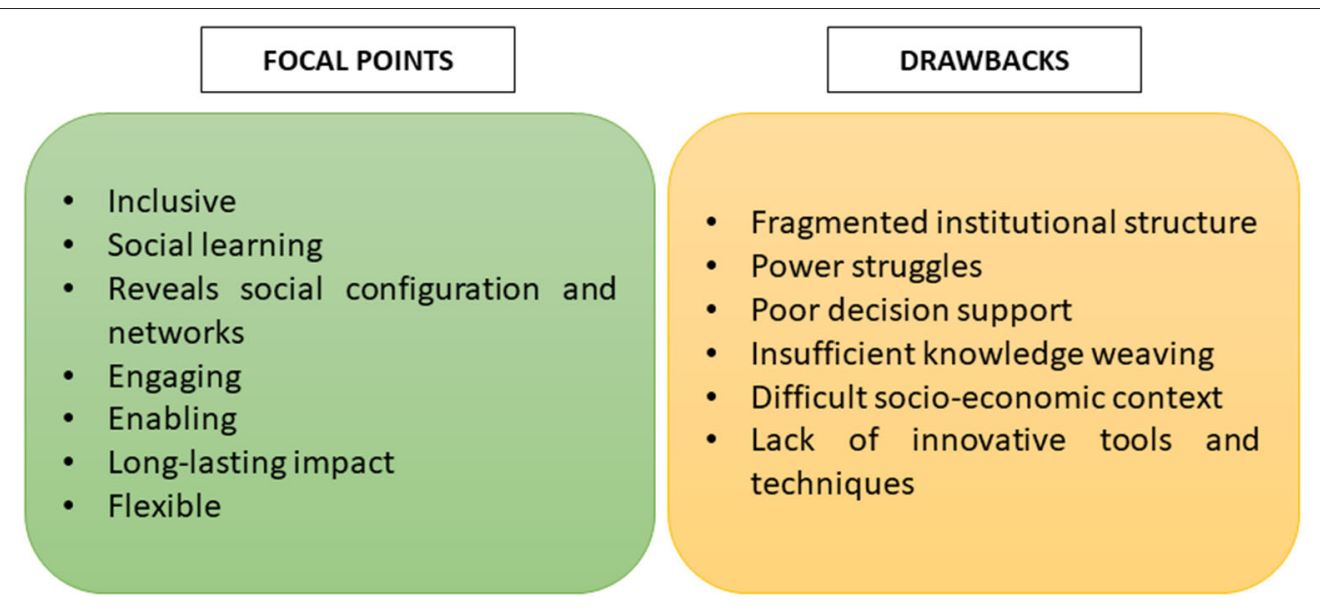

FIGURE 1 | Summary of the focal points and drawbacks of a co-design process to address NBS for inclusive urban planning.

initiatives might only include limited points of view from a certain type of participant rather than from a full spectrum of society.

Fragmented institutional structures, power struggles between stakeholders or authorities as well as insufficient data about existing ES over a territory (Mascarenhas et al., 2016), limited social networks or poor decision-support (Albert et al., 2019) are also important challenges that affect co-design and planning decisions. A lack of experience as well as missing knowledge about methods and techniques are important barriers too when incorporating co-design results and societal demands in planning, at various territorial scales and institutional levels, but is not a reason not to try. In addition, since "green planning" is often undertaken at different levels, one scale might benefit more than others from co-design. For example, increasing green infrastructure at a local scale (i.e., school grounds, street-scene or neighborhood) can add up to greater positive impacts in a greater scale, but may also result in situations where trade-offs are "exported" to other local settings, e.g., the space needed for gray infrastructure. This calls for a broad perspective also in local co-design based planning. Finally, planning systems often benefit from having "change agents" within them, whose job is to break up established top-down communication channels and to facilitate local but also "inter local" regional communication and exchange on planning.

Insufficient knowledge weaving (Tengö et al., 2017) can be another drawback, present at various levels and different stages of the co-design process. For example, a successful co-design should dispose by a correct translation from the very beginning, i.e., capacity of adapting knowledge and communication using terms than can be understood by all authors. In this way, co-design enables equitable and empowering knowledge-sharing processes.

Difficult socio-economic contexts can also limit the potential of a co-design process. In certain regions, mentalities are difficult to be changed and business-as-usual economic development prevails in institutional actions and urban planning. Even if citizens then argue for a greater development of NBS, citizens' voice is often not heard, and the transformative potential of the co-design process is limited.

At least in some parts of Europe, including NBS into planning might be synonymous to preserving the already existing green (i.e., peri-urban green threatened by urbanization). In that cases, creating awareness and making existing connections to green space visible are crucial for the co-design process. Solid communication strategies should accompany the codesign session, contributing to learning about the importance of green space and its properties, including natural and cultural specificities.

\section{DISCUSSION AND CONCLUSIONS}

A successful co-design strategy that mainstreams NBS into planning is one that enables outcomes that matter to participants, and that gives voice to all concerned societal groups and understands stakeholders' and citizens' needs and demands. It enables knowledge generation and exchange, mutual learning through social networks, and needs to be flexible with regard to planning decisions and focus over time (Figure 1). We strongly believe that citizen science activities and innovative techniques (i.e., using visual thinking), together with experienced facilitators (for the "flipped classroom"), enable collaboration and engagement of a good quality co-design. The socio-ecological context is important too: landscape characteristics including biodiversity and relevant ecosystem services, but also the specific social structures-including inequities-in the respective area should be accounted for in the co-design process. Limitations can arise when the stakeholders mapping is too narrow or focuses on certain socio-economic contexts or expectations about relevant groups and their preferences, while at the same time societies change and pluralize in life styles, and dynamic land-use changes are occurring.

Finally, we feel that successful co-design in transformative urban greening is one that enables an outcome beyond 
the project, based on citizens' involvement and demandscreating a lasting community around an NBS. Innovative dynamics and other ancillary methodologies (i.e., citizens' science) should accompany any co-design process, to enforce participation, raise awareness and stakeholders' engagement, and with that increases the chances of a long-lasting societal legacy benefitting both nature and people.

\section{AUTHOR CONTRIBUTIONS}

$\mathrm{CB}$ decided the co-design focus and developed the paper. JP helped with issues related to urban planning and socio-economic context. CD contributed to introduction, shaped the governance part, and developed the limitations of co-design. GW draw the main definition and characteristics of the co-design, helped

\section{REFERENCES}

Abeysekera, L., and Dawson, P. (2015). Motivation and cognitive load in the flipped classroom: Definition, rationale and a call for research. High. Educ. Res. Dev. 34, 1-14. doi: 10.1080/07294360.2014.934336

Albert, C., Schröter, B., Haase, D., Brillinger, M., Henze, J., Herrmann, S., et al. (2019). Addressing societal challenges through nature-based solutions: How can landscape planning and governance research contribute? Landsc. Urban Plan 182, 12-21. doi: 10.1016/j.landurbplan.2018.10.003

Bodin, Ö., and Crona, B. I. (2009). The role of social networks in natural resource governance: what relational patterns make a difference? Glob. Environ. Change 19, 366-374. doi: 10.1016/j.gloenvcha.2009.05.002

De Vreese, R., Fu, W., Maurice, S., Schante, J., Malandrino, C., and Jin, J. (2020). Guidance document for the local co-design and co-learning workshops (including local stakeholder analysis). CLEARING HOUSE D3.1 - guidance document. doi: 10.5281/zenodo.3887161

De Vreese, R., Leys, M., Fontaine, C. M., and Dendoncker, N. (2016). Social mapping of perceived ecosystem services supply-The role of social landscape metrics and social hotspots for integrated ecosystem services assessment, landscape planning and management. Ecol. Indic. 66, 517-533. doi: 10.1016/j.ecolind.2016.01.048

De Vreese, R., Van Herzele, A., Dendoncker, N., Fontaine, C. M., and Leys, M. (2019). Are stakeholders' social representations of nature and landscape compatible with the ecosystem service concept? Ecosyst. Serv. 37:100911. doi: 10.1016/j.ecoser.2019.100911

Derks, J., Giessen, L., and Winkel, G. (2020). Nature recreation in times of social distancing - Booming visits during the COVID-19 pandemic reveal forests as critical infrastructure. For. Policy Econ. 118:102253. doi: 10.1016/j.forpol.2020.102253

Ernstson, H., Sorlin, S., and Elmqvist, T. (2008). Social movements and ecosystem services - the role of social network structure in protecting and managing urban green areas in Stockholm. Ecol. Soc. 13:39. doi: 10.5751/ES-02589-130239

Fischer, L. K., Brinkmeyer, D., Josefine Karle, S., Cremer, K., Huttner, E., Seebauer, M., et al. (2018). Biodiverse edible schools: Linking healthy food, school gardens and local urban biodiversity. Urban For. Urban Gree. 40, 35-43. doi: 10.1016/j.ufug.2018.02.015

Fish, R., Church, A., and Winter, M. (2016). Conceptualising cultural ecosystem services: a novel framework for research and critical engagement. Ecosyst. Serv. 21, 208-207. doi: 10.1016/j.ecoser.2016.09.002

Grechyna, D. (2020). Health Threats Associated with Children Lockdown in Spain during COVID-19 SSRN. Available online at: https://ssrn.com/ abstract $=3567670$ or http://dx.doi.org/10.2139/ssrn.3567670 (accessed April 7, 2020).

Kabisch, N., Frantzeskaki, N., Pauleit, S., Naumann, S., Davis, M., Artmann, M., et al. (2016). Nature-based solutions to climate change mitigation and shaping the strengths and limitations of the process, and added references. $\mathrm{RD}$ contributed to the main characteristics of the whole co-design process, added referenced contributions, and revised the text. All the authors actively helped clarifying the main ideas and made important contributions to the body of the text.

\section{ACKNOWLEDGMENTS}

The CLEARING HOUSE project has received funding from the European Union's Horizon 2020 research and innovation programme under grant agreement No 821242. The content of this document reflects only the authors' view. The European Commission is not responsible for any use that may be made of the information it contains. adaptation in urban areas: perspectives on indicators, knowledge gaps, barriers, and opportunities for action. Ecol. Soc. 21:39. doi: 10.5751/ES-08373-210239

Karrasch, L., Maier, M., Kleyer, M., and Klenke, T. (2017). Collaborative landscape planning: Co-design of ecosystem-based land management scenarios. Sustainability 9, 1-15. doi: 10.3390/su9091668

Louv, R. (2005). Nature deficit. Orion 70-71.

Mascarenhas, A., Ramos, T. B., Haase, D., and Santos, R. (2016). Participatory selection of ecosystem services for spatial planning: Insights from the Lisbon Metropolitan Area. Portugal. Ecosyst. Serv. 18, 87-99. doi: 10.1016/j.ecoser.2016.02.011

O’Brien, L., De Vreese, R., Atmiş, E., Olafsson, A. S., Sievänen, T., Brennan, M., et al. (2017). "Social and environmental justice: diversity in access to and benefits from urban green infrastructure-examples from Europe," in The Urban Forest. (Cham: Springer), 153-190. doi: 10.1007/978-3-319-50280-9_15

Pauleit, S., Zölch, T., Hansen, R., Randrup, T. B., and van den Bosch, C. K. (2017). "Nature-based solutions and climate change-four shades of green," in Nature-Based Solutions to Climate Change Adaptation in Urban Areas: Linkages Between Science, Policy and Practice, eds N, Kabisch, H, Korn, J Stadler, A, Bonn (Berlin: Springer), 29-49. doi: 10.1007/978-3-319-56091-5_3

Raymond, C. M., Berry, P., Breil, M., Nita, M. R., Kabisch, N., de Bel, M., et al. (2017). An Impact Evaluation Framework to Support Planning and Evaluation of Nature-Based Solutions Projects. Report prepared by the EKLIPSE Expert Working Group on Nature-based Solutions to Promote Climate Resilience in Urban Areas. Centre for Ecology \& Hydrology, Wallingford, United Kingdom.

Szebeko, D., and Tan, L. (2010). Co-designing for society. Australasian Med. J. 3, 580-590. doi: 10.4066/AMJ.2010.378

Tengö, M., Hill, R., Malmer, P., Raymond, C. M., Spierenburgm, M., Danielsen, F., et al. (2017). Weaving knowledge systems in IPBES, CBD and beyond-lessons learned for sustainability. Curr. Opin. Env. Sust. 26, 17-25. doi: 10.1016/j.cosust.2016.12.005

Webb, R., Rissik, D., Petheram, L., Beh, J.-L., and Smith, M. S. (2019). Codesigning adaptation decision support: meeting common and differentiated needs. Climatic Change 153, 569-585. doi: 10.1007/s10584-018-2165-7

Conflict of Interest: The authors declare that the research was conducted in the absence of any commercial or financial relationships that could be construed as a potential conflict of interest.

Copyright (c) 2020 Basnou, Pino, Davies, Winkel and De Vreese. This is an openaccess article distributed under the terms of the Creative Commons Attribution License (CC BY). The use, distribution or reproduction in other forums is permitted, provided the original author(s) and the copyright owner(s) are credited and that the original publication in this journal is cited, in accordance with accepted academic practice. No use, distribution or reproduction is permitted which does not comply with these terms. 